\title{
Severe cardiovascular involvement in Hughes-Stovin syndrome
}

\author{
Patrick Groga-Bada ${ }^{1}$, Bernhard Klumpp ${ }^{2}$, Christian La Fougère ${ }^{2}$, Konstantin Nikolaou ${ }^{2}$, Christian Eick ${ }^{1}$, Meinrad \\ Gawaz $^{* 1}$, Theodoros Xenitidis ${ }^{3}$ \\ ${ }^{1}$ University Hospital, Department of Cardiology and Cardiovascular Medicine, Eberhard Karls University Tuebingen, Tuebingen, \\ Germany \\ ${ }^{2}$ University Hospital, Department of Radiology and Nuclear Medicine, Eberhard Karls University Tuebingen, Tuebingen, Germany \\ ${ }^{3}$ University Hospital, Department of Internal Medicine II (Oncology, Hematology, Rheumatology, Immunology, Pneumology), \\ Eberhard Karls University Tuebingen, Tuebingen, Germany
}

Received: September 23, 2017

DOI: $10.5430 /$ crim.v4n4p52
Accepted: October 30, 2017

Online Published: November 16, 2017

URL: https://doi.org/10.5430/crim.v4n4p52

\begin{abstract}
Hughes-Stovin syndrome (HSS) is a rare autoimmune vasculitis and is characterized by the simultaneous presence of deep venous thrombosis and pulmonary artery aneurysms. The exact etiology and pathogenesis of this life-threatening syndrome is currently unknown. The disease is thought to be a variant of Behcet's disease with major vascular involvement. Here we report a case of a 19-year-old man from West Africa with a severe cardiovascular manifestation of HSS. The patient was referred to our hospital with dyspnoea, recurrent fever and swelling of the left leg. Echocardiography revealed extensive biventricular thrombi. He responded very well to immunosuppressive therapy in combination with anticoagulation using low-molecular-weight heparins (LMWHs). Thrombolysis was consciously avoided.
\end{abstract}

Key Words: Pulmonary artery aneurysms, Biventricular thrombi, Behçet's disease

\section{INTRODUCTION}

Hughes-Stovin syndrome is a rare autoimmune vasculitis that affects the blood vessels with inflammation. The disease is characterized by the simultaneous presence of deep venous thrombosis and one or multiple pulmonary artery aneurysms. ${ }^{[1]}$ The syndrome was first described in 1959 by the two British physicians John Patterson Hughes and Peter George Ingle Stovin and named after them. ${ }^{[1]}$ Hughes-Stovin syndrome is yet considered to be a cardiovascular variant of Behçet's disease. ${ }^{[1-3]}$ Typically young men between the second and fourth decades are affected ${ }^{[4-7]}$ The prevalence of the disease worldwide is less than $1: 1,000,000,{ }^{[4]}$ making it extremely rare. The clinical symptoms are recurrent fever, chills, peripheral venous thrombosis, multiple pulmonary artery aneurysms, cough, fatigue, dyspnea, chest pain and hemoptysis. ${ }^{[5-7]}$ Further, nearly all patients with Behçet's disease present oral mucocutaneous ulcerations in the form of aphthous ulcers. Additionally, patients may present with genital ulcers, erythema nodosum, cutaneous pustular vasculitis or uveitis. ${ }^{[8]}$ Here we report a case of a 19 -year-old man from West Africa with a striking cardiovascular manifestation of Hughes-Stovin syndrome.

\footnotetext{
*Correspondence: Meinrad Gawaz; Email: meinrad.gawaz@med.uni-tuebingen.de; Address: Department of Cardiology and Cardiovascular Medicine, Eberhard Karls University Tuebingen, Otfried Müller Straße 10, 72076 Tübingen, Germany.
} 


\section{CASE PResentation}

A previously healthy and athletic 19-year-old man from Gambia, West Africa, was referred to our hospital with recurrent fever and swelling of the left leg. He presented to our emergency room with dyspnea on exertion (NYHA III) and malaise for the last two months. Four weeks prior to hospital admission he noticed genital ulcerations (glans penis and scrotum) as well as lymph node swelling in both groins. He denied any sexual contact in the last two years. Previous oral ulcers were also known. The patient immigrated to Germany as a refugee one year prior. On admission, he was tachycardic $116 \mathrm{bpm}$ and febrile to $38.6^{\circ} \mathrm{C}$. His blood pressure was $106 / 62 \mathrm{mmHg}$. The clinical examination showed a low systolic heart sound over Erb point and a pronounced swelling of the left upper and left lower limb as well as slight ankle edema of the left leg. He had bilateral inguinal
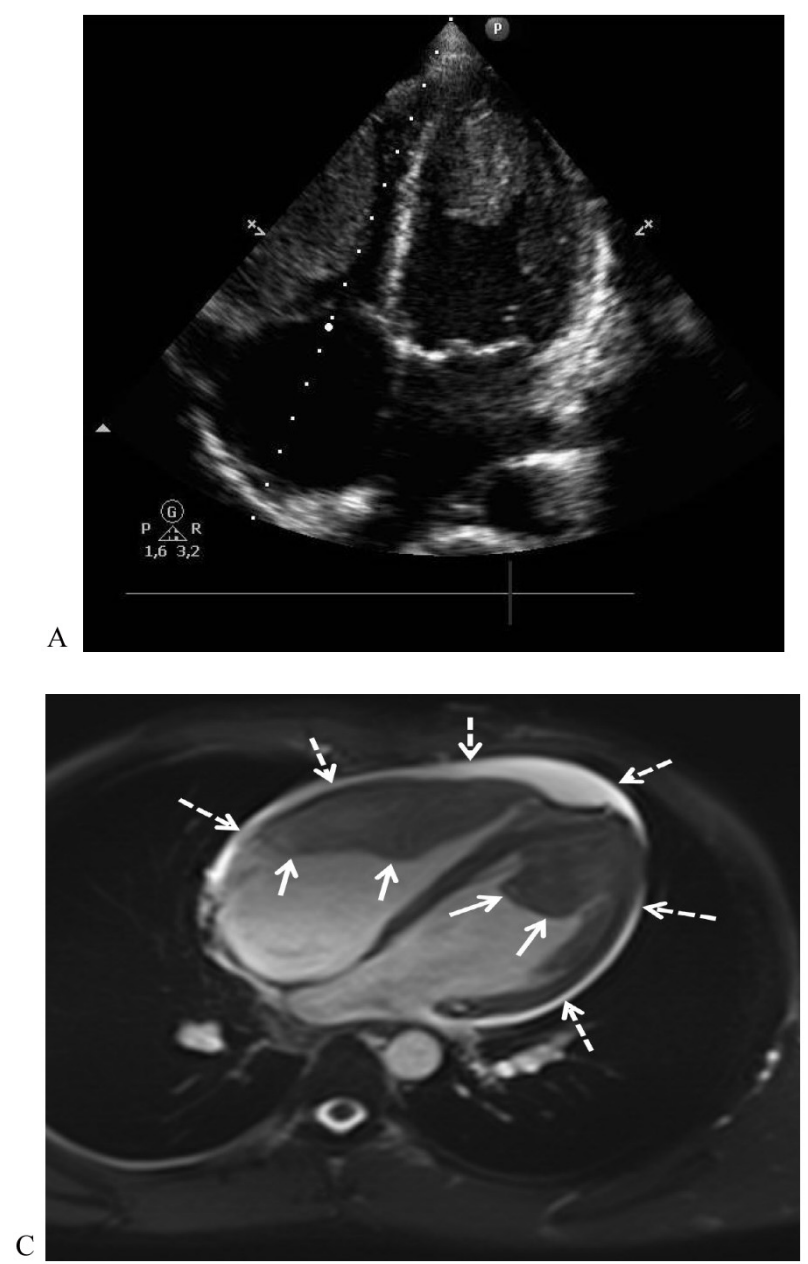

lymphadenopathy. Skin examination revealed cured genital, healing oral aphthous ulcers and extensive pityriasis versicolor of the trunk (as a coincidence).

Laboratory studies showed a microcytic anemia (hemoglobin: $8.5 \mathrm{~g} / \mathrm{dl}, \mathrm{MCV}: 78.0 \mathrm{fl}$ ), a regular white blood cell count $(8,720 / \mu 1)$, normal platelet count $(220,000 / \mu 1)$, elevated Creactive protein $(15.3 \mathrm{mg} / \mathrm{dl})$, an elevated erythrocyte sedimentation rate $(54 \mathrm{~mm} / \mathrm{h})$ and procalcitonin $(0.28 \mathrm{ng} / \mathrm{ml})$ and an elevated lactate dehydrogenase (262 U/l). The troponin I test was within normal limits. Further coagulation testing indicated regular INR, partial thromboplastin time (PTT), antithrombin III however low elevated fibrinogen $(443 \mathrm{mg} / \mathrm{dl})$ and significantly elevated D-dimer $(5.5 \mu \mathrm{g} / \mathrm{mL}$ ) (see Table 1). Blood cultures and serology for hepatitis B, C, HIV were negative. Malaria, syphilis and schistosomiasis blood tests also provided negative results.
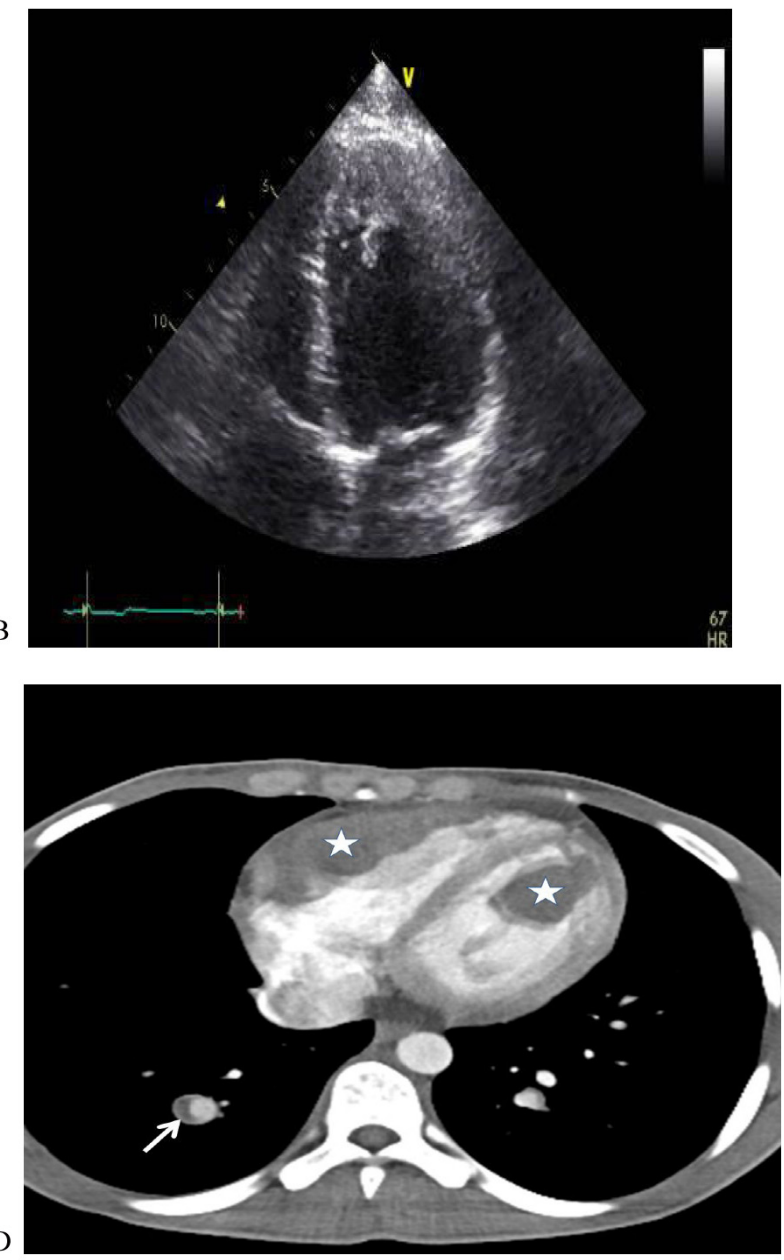

Figure 1. Transthoracic echocardiograms (TTE) show the presence of biventricular thrombi (4-chamber view) prior therapy (A) and 4 months later (B). (C) Cine SSFP MR image in the four chamber view confirmed the presence of biventricular thrombi as well as circular pericardial effusion. (D) Contrast-enhanced CT shows ventricular thrombosis concordant with MRI and TTE (asterisk). A segmental branch of the right lower lobe pulmonary artery exhibits an aneurysm with partial thrombosis (arrow). 
Table 1. Results of the laboratory test (in red marked the parameters that are higher/lower in comparison to reference range values)

\begin{tabular}{|c|c|c|c|}
\hline Laboratory & Parameters & Value unit & Reference \\
\hline \multicolumn{4}{|l|}{ Blood sedimentation rate } \\
\hline BSR 1 Hour & 54 & $\mathrm{~mm}$ & $0-15$ \\
\hline \multicolumn{4}{|l|}{ Differential hematopoietic } \\
\hline Leucocytes & 8,720 & $1 / \mu \mathrm{l}$ & $3,800-10,300$ \\
\hline Neutrophiles abs & 5.14 & $1,000 / \mu 1$ & $1.8-7.0$ \\
\hline Lymphocytes abs & 0.98 & $1,000 / \mu 1$ & $1.1-3.2$ \\
\hline Monocytes abs & 0.71 & $1,000 / \mu 1$ & $0.26-0.87$ \\
\hline Basophiles abs & 0.03 & $1,000 / \mu 1$ & $0.02-0.11$ \\
\hline immature granulocytes abs & 0.05 & $1,000 / \mu 1$ & $0-0.06$ \\
\hline Neutrophiles & 73.5 & $\%$ & $40.0-80.0$ \\
\hline Lymphocytes & 14.0 & $\%$ & $20.0-45.0$ \\
\hline Monocytes & 10.1 & $\%$ & $2.0-13$ \\
\hline Eosinophiles & 2.0 & $\%$ & $0.5-8$ \\
\hline Basophiles & 0.4 & $\%$ & $\max .2 .0$ \\
\hline Normoblasts abs & 0.01 & $1,000 / \mu \mathrm{l}$ & $0-0.1$ \\
\hline Normoblasts & 0.1 & $\%$ & $0-1$ \\
\hline Erythrocytes & 3.36 & $\mathrm{Mio} / \mu \mathrm{l}$ & $4.2-6.2$ \\
\hline Hematocrit & 26.2 & $\%$ & $42.0-52.0$ \\
\hline Hemoglobin level & 8.5 & $\mathrm{~g} / \mathrm{dl}$ & $14.0-18.0$ \\
\hline $\mathrm{MCH}$ & 25.3 & pg & $27.0-34.0$ \\
\hline $\mathrm{MCHC}$ & 32.4 & $\mathrm{~g} / \mathrm{dl}$ & $32.0-36$ \\
\hline $\mathrm{MCV}$ & 78.0 & $\mathrm{fl}$ & $80-93$ \\
\hline RDW & 14.0 & $\%$ & $\max .15$ \\
\hline Thrombocytes & 220 & $1.000 / \mu 1$ & $140-392$ \\
\hline \multicolumn{4}{|l|}{ Clotting } \\
\hline Quick & 65 & $\%$ & $70-120$ \\
\hline INR & 1.2 & & \\
\hline PTT & 30 & $\sec$ & $\max .40$ \\
\hline Fibrinogen & 443 & $\mathrm{mg} / \mathrm{dl}$ & $170-410$ \\
\hline Antithrombin III (AT III) & 88 & $\%$ & $85-115$ \\
\hline \multicolumn{4}{|l|}{ Electrolytes } \\
\hline Sodium & 136 & $\mathrm{mmol} / 1$ & $136-148$ \\
\hline Potassium & 4.3 & $\mathrm{mmol} / \mathrm{l}$ & $3.5-4.8$ \\
\hline Calcium & 1.9 & $\mathrm{mmol} / \mathrm{l}$ & $2.1-2.6$ \\
\hline Magnesium & 0.95 & $\mathrm{mmol} / 1$ & $0.7-1.0$ \\
\hline Kreatinin & 0.8 & $\mathrm{mg} / \mathrm{dl}$ & $0.6-1.1$ \\
\hline GFR - MDRD & 124.5 & $\mathrm{ml} / \mathrm{min} / 1.73 \mathrm{~m}^{2}$ & $\min .>60$ \\
\hline GFR - CKD-EPI & $>90$ & $\mathrm{ml} / \mathrm{min} / 1.73 \mathrm{~m}^{2}$ & \\
\hline Bilirubin, overall & 0.4 & $\mathrm{mg} / \mathrm{dl}$ & $\max .1 .1$ \\
\hline Overall-Protein & 8.3 & $\mathrm{~g} / \mathrm{dl}$ & $6.5-8.5$ \\
\hline Albumin & 3.2 & $\mathrm{~g} / \mathrm{dl}$ & $3.0-5.0$ \\
\hline C-reactive Protein (CRP) & 15.36 & $\mathrm{mg} / \mathrm{dl}$ & $\max .0 .50$ \\
\hline Procalcitonin & 0.28 & $\mathrm{ng} / \mathrm{ml}$ & $\max .0 .1$ \\
\hline \multicolumn{4}{|l|}{ Troponin I } \\
\hline Troponin I & $<0.03$ & $\mu \mathrm{g} / 1$ & $\max .0 .04$ \\
\hline \multicolumn{4}{|l|}{ Enzymes } \\
\hline Creatine Kinase (CK) & 66 & $\mathrm{U} / 1$ & $\max .190$ \\
\hline GOT/AST & 19 & $\mathrm{U} / 1$ & $\max .50$ \\
\hline GPT/ALT & 12 & $\mathrm{U} / 1$ & $\max .50$ \\
\hline Alkaline Phosphatase (AP) & 88 & $\mathrm{U} / 1$ & $40-130$ \\
\hline Lactate dehydrogenase (LDH) & 262 & $\mathrm{U} / 1$ & $\max .250$ \\
\hline Gamma-Glutamyl-Transferase (GGT) & 45 & $\mathrm{U} / 1$ & $\max .40$ \\
\hline Cholinesterase (CHE) & 4.8 & $\mathrm{kU} / 1$ & $4.9-12.0$ \\
\hline Lipase & 50 & $\mathrm{U} / 1$ & $\max .60$ \\
\hline \multicolumn{4}{|l|}{ Hormones } \\
\hline T4 value & 12 & $\mathrm{pmol} / 1$ & $12-23$ \\
\hline T3 value & 2.8 & $\mathrm{pmol} / 1$ & $3.5-6.5$ \\
\hline $\mathrm{TSH}$ & 1.00 & $\mathrm{mU} / 1$ & $0.4-2.5$ \\
\hline
\end{tabular}


ECG on admission depicted sinus rhythm with T-wave inversion in lead III, V2 to V4 with PR interval of $124 \mathrm{~ms}$, QRS 86 $\mathrm{ms}$ and QT interval of $352 \mathrm{~ms}$. Echocardiography revealed extensive biventricular thrombus deposits (see Figure 1A). Whole body computed tomography and cardiac magnetic resonance imaging confirmed the presence of biventricular thrombi (see Figure 1C, 1D) and disclosed pulmonary artery emboli in the right pulmonary artery, left lower lobe artery, right lower lobe artery and all segmental branches, lingual artery, right upper lobe artery, left segment $2 / 3$ artery (see Figure $2 \mathrm{~A}$ ), with associated pulmonary infarction in the right lower lobe (see Figure 2B).

A

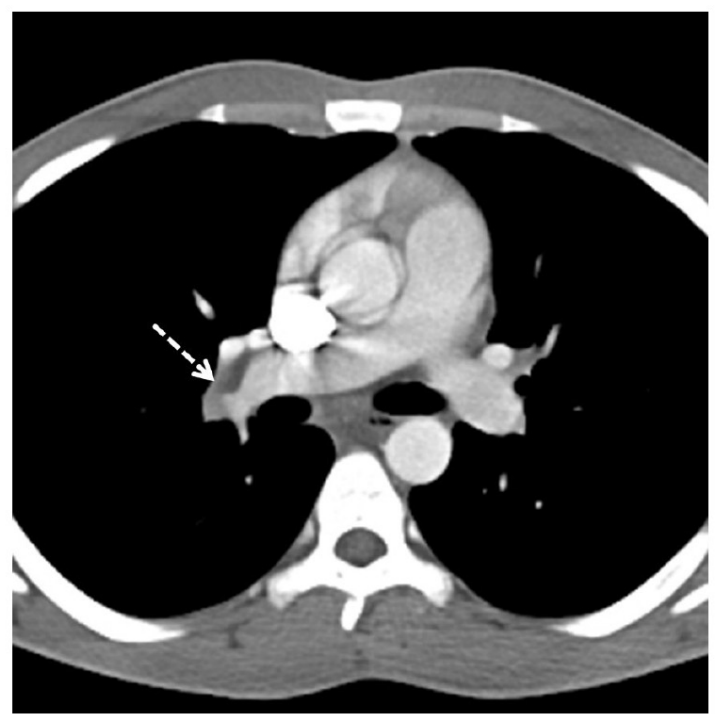

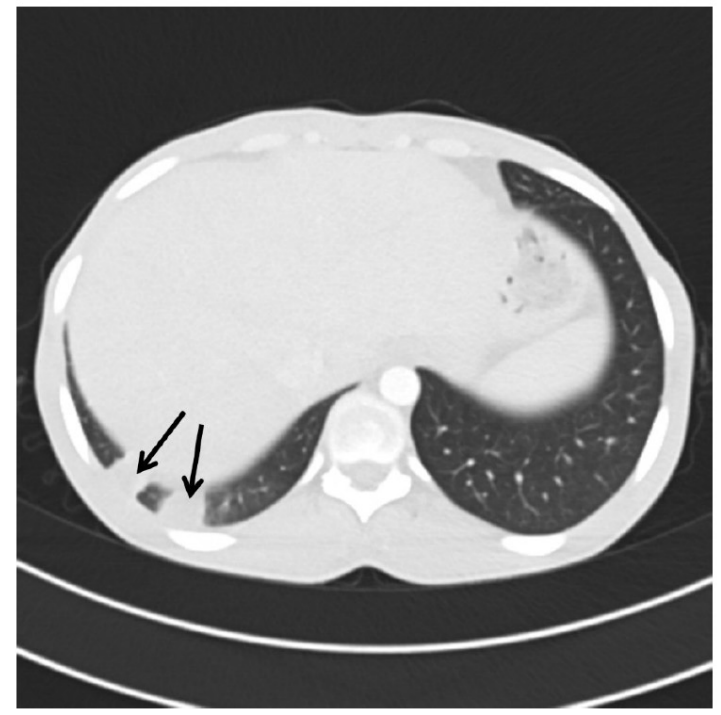

B

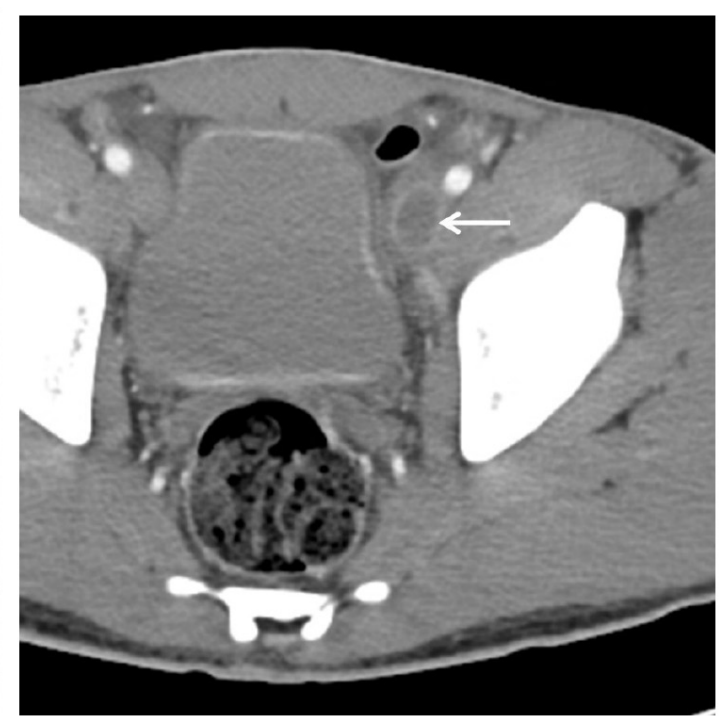

C

Figure 2. (A) CT: The right central pulmonary artery is partially obstructed by a wall adherent embolus. (B) CT: Hampton humps (black arrows) in the periphery of the right lower lobe indicate pulmonary infarction subsequent to pulmonary embolism. (C) CT: It shows the thrombosis in the left external iliac vein (arrow).

Furthermore two pulmonary artery aneurysms were detected in the right lung in segment ten bilateral (see Figure 1D). Deep venous thrombosis of the left external iliac vein and left common femoral vein (see Figures 2C, 3A) were also diagnosed. ${ }^{18} \mathrm{~F}$-fluorodeoxyglucose positron emission tomography/CT performed after 16 days demonstrated regression of the thrombus deposits in the left and right ventricle Published by Sciedu Press as well as in the pulmonary artery aneurysms (see Figure 3B). Moderately increased FDG uptake in the vessel wall of the larger pulmonary artery aneurysm in the right lower lobe indicated the presence of inflammation. After 27 days, the regression of the FDG uptake in the aneurysmatic vessel wall provided evidence for resolution of inflammation under anti-inflammatory therapy. 


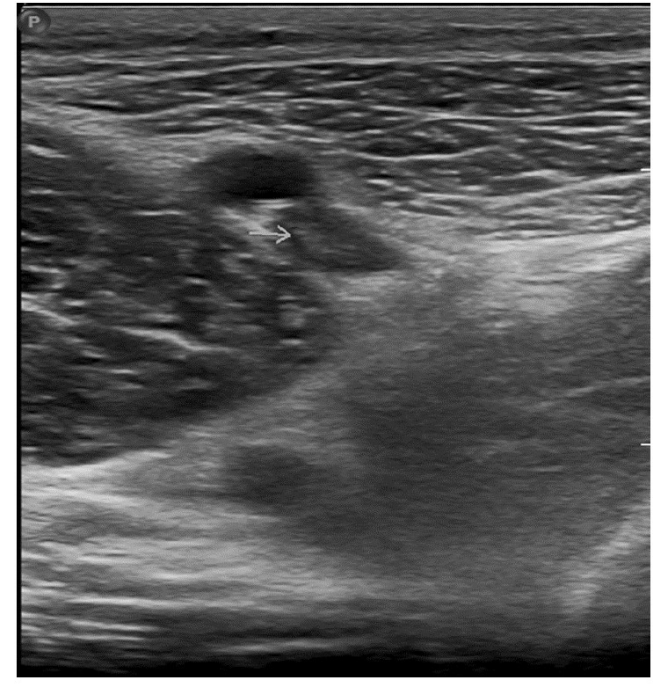

A

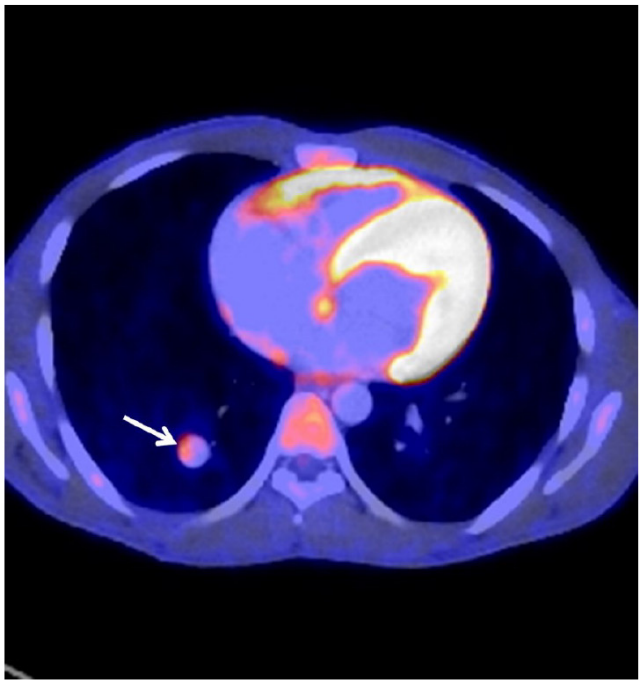

B

Figure 3. (A) Venous Doppler: shows the thrombosis in the left common femoral vein. (B) PET-CT-Scan: Slightly increased ${ }^{18} \mathrm{~F}$ FDG uptake of the aneurysm on PET/CT performed 16 days after initial diagnosis indicates moderate inflammation of the vessel wall (arrow).

The clinical symptoms comprising recurrent fever, fatigue, sis and pulmonary artery aneurysms suggested the diagnosis oral and genital aphthous ulcers (see Figure 4), chest pain, of HSS as part of Behcet's disease. dyspnoea and malaise accompanied by multifocal thrombo-

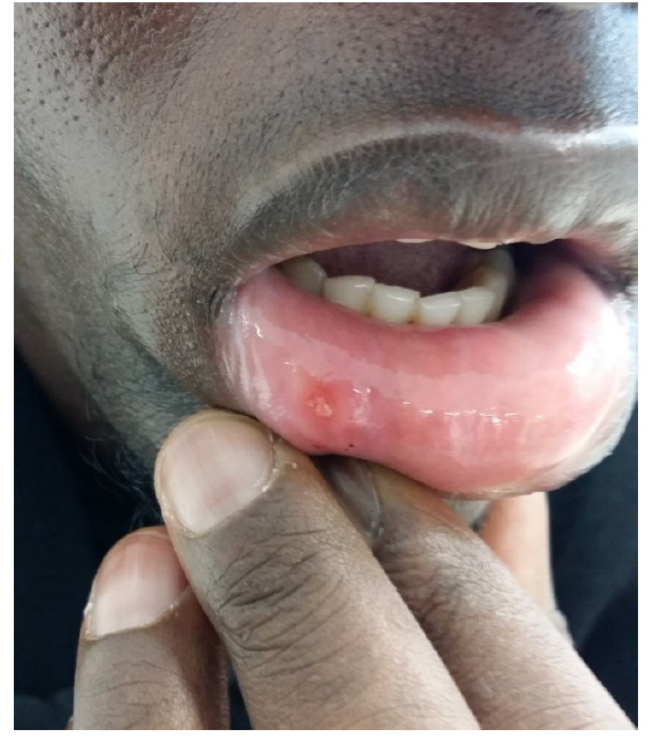

A

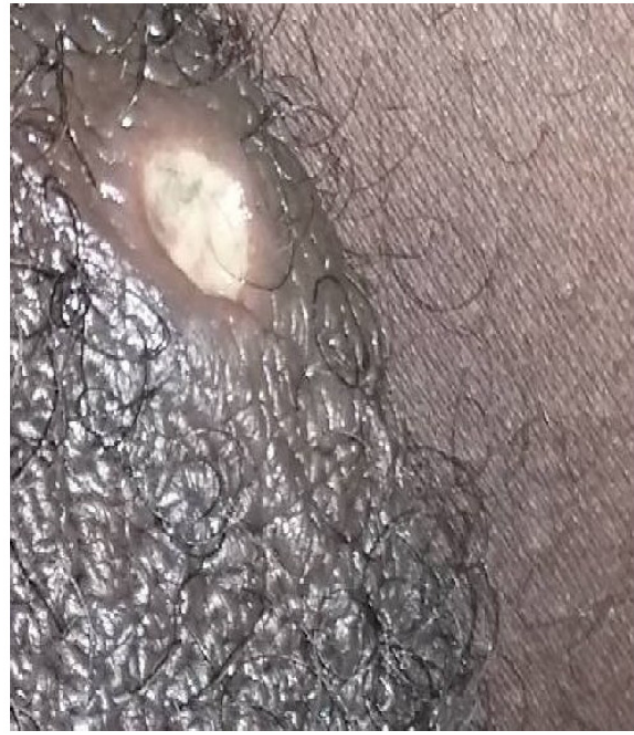

B

Figure 4. (A) The picture shows an oral aphthous ulcer prior therapy. (B) The picture reveals the clinical occurrence of genital aphthous ulcer.

To prevent progressive thrombosis and consecutive thromboembolism anticoagulation therapy with low molecular heparin was initiated. Due to an increased risk of fatal haemorrhage by rupture of the pulmonary artery aneurysms we avoided any thrombolytic therapy regimen. The immunosup- pressive therapy consisted of $250 \mathrm{mg}$ hydrocortisone intravenous for three days followed by $1 \mathrm{mg} / \mathrm{kg}$ bodyweight/day with a weekly reduction by $10 \mathrm{mg}$ and a single dose of $750 \mathrm{mg} / \mathrm{m}^{2}$ cyclophosphamide. After four weeks the patient had considerably improved. Echocardiographic controls re- 
vealed a substantial regression of the biventricular thrombi on continuous LMH anticoagulation (see Figure 1B). Concordantly PET/CT demonstrated thrombus regression within the pulmonary artery aneurysms. Decreasing FDG uptake of the aneurysmatic vessel wall represented remission of inflammatory activity due to anti-inflammatory therapy. Presenting manifestations of a disease relapse (gonarthritis, scrotal ulcers, elevated inflammation markers) we intensified the immunosuppression by giving infliximab (a chimeric monoclonal antibody antagonizing tumour necrosis factor alpha $[\mathrm{TNF}-\alpha]$ ) as add on therapy. As far as inflammation will recover completely a maintenance therapy with azathioprine should be started.

Our patient presented with an unusual severe expression of the disease with the occurrence of biventricular thrombi, deep vein thrombosis, pulmonary embolism and substantial pulmonary artery aneurysm. The treatment is based on corticosteroids and immunosuppressants to control inflammation and stabilize pulmonary artery aneurysms. ${ }^{\left[{ }^{8-10]}\right.}$ Thrombolysis is usually not recommended. ${ }^{[7]}$ Three months after initial hospital admission, the patient is in a physically good condition, anticoagulation is well tolerated and effective in reducing intracardial thrombi. Inflammation is well controlled under therapy with cyclophosphamide $\left(750 \mathrm{mg} / \mathrm{m}^{2}\right.$ every three weeks) and infliximab (as add on therapy).

\section{DisCUSSION}

Besides immunosuppressive therapy, anticoagulation can be recommended to prevent thrombus growth and thromboembolism. As the presence of pulmonary artery aneurysms comes along with the risk of vessel rupture and substantial bleeding, anticoagulation has to be carefully evaluated. However, we considered our patient at high risk for thromboembolism and stroke due to extensive biventricular thrombus deposits and therefore decided to initiate anticoagulation. Depending on the extent of pulmonary artery aneurysm and potential bleeding, surgical resection or angiographic embolization might be considered. ${ }^{[11,12]}$ In cases of inadequate cyclophosphamide response TNF- $\alpha$-Antagonists (alone or in combination with cyclophosphamide) may offer a solution in managing life-threatening complications. ${ }^{[13]}$

\section{CONSENT}

Signed informed consent was obtained from the patient for publication of this case report.

\section{CONFlicts OF INTEREST Disclosure}

The authors have declared no conflicts of interest.

\section{REFERENCES}

[1] Hughes JP, Stovin PG. Segmental pulmonary artery aneurysm with peripheral venous thrombosis. Br J Dis Chest. 1959 Jan; 53(1): 19-27. https://doi.org/10.1016/S0007-0971(59)80106-6

[2] Erkan D, Yazici Y, Sanders A, et al. Is Hughes-Stovin syndrome Behcet's disease? Clin Exp Rheumatol. 2004; 22 (Suppl. 34): S64-8. PMid:15515789

[3] Durieux P, Bletry O, Huchon G, et al. Multiple pulmonary arterial aneurysms in Behcet's disease and Hughes-Stovin syndrome. Am J Med. 1981 Oct; 71(4): 736-41. https://doi.org/10.1016/00 02-9343(81) 90245-X

[4] Chalazonitis AN, Lachanis SB, Mitseas P, et al. Hughes-Stovin syndrome: a case report and review of the literature. Cases J. 2009 Jan 29; 2: 98. PMid:19178695 https://doi.org/10.1186/1757-1 626-2-98

[5] Chung MP, Yi CA, Lee HY, et al. Imaging of pulmonary vasculitis. Radiology. 2010 May; 255(2): 322-41. PMid:20413748 https://doi.org/10.1148/radiol.10090105

[6] El Aoud S, Frikha F, Snoussi M, et al. Moderate hemoptysis caused by Hughes-Stovin syndrome. Clin Pract. 2014 Nov 6; 4(3): 647. PMid:25568765 https://doi.org/10.4081/cp.2014.647

[7] Khalid U, Saleem T. Hughes-Stovin syndrome. Orphanet J Rare Dis. 2011 Apr 13; 6: 15. PMid:21489283 https://doi.org/10.118 6/1750-1172-6-15
[8] Hatemi G, Silman A, Bang D, et al. EULAR recommendations for the management of Behcet disease. Ann Rheum Dis. 2008 Dec; 67(12): 1656-62. PMid:18245110 https://doi.org/10.1136/ ard. 2007.080432

[9] Wechsler B, Vidailhet M, Piette JC, et al. Cerebral venous thrombosis in Behcet's disease: clinical study and long term follow-up of 25 cases. Neurology. 1992 Mar; 42(3 Pt 1): 614-8. PMid:1549224 https://doi.org/10.1212/WNL.42.3.614

[10] Weintraub JL, DeMayo R, Haskal ZJ, et al. SCVIR annual meeting film panel session: diagnosis and discussion of case 1: HughesStovin syndrome. J Vasc Interv Radiol. 2001 Apr; 12(4): 531-4. https://doi.org/10.1016/S1051-0443(07)61897-1

[11] Ribeiro BN, Ribeiro RN, Zanetti G, et al. Hughes-Stovin syndrome: an unusual cause of pulmonary artery aneurysms. Radiol Bras. 2016 May-Jun; 49(3): 202-3. PMid:27403026 https : //doi.org/10.1 590/0100-3984.2015.0048

[12] Mahfoudhi M, Turki S. A Pulmonary Aneurysm: Don't Forget Hughes-Stovin Syndrome. Pan Afr Med J. 2015 Apr 30; 20: 445. PMid:26309477 https://doi.org/10.11604/pamj . 2015 .20 .445 .5938

[13] Hamuryudan V, Seyahi E, Ugurlu S, et al. Pulmonary artery involvement in Behçet's syndrome: Effects of anti-Tnf treatment. Semin Arthritis Rheum. 2015 Dec; 45(3): 369-73. PMid:26190564 https://doi.org/10.1016/j.semarthrit.2015.06.008 